\title{
Influence of Reaction Time and Synthesis Temperature on Physical Properties of ZnO Nanoparticles Synthesized by Hydrothermal Method
}

\author{
H.S. Wasly*1, M.S. Abd El-Sadek ${ }^{2,3}$, Mohamed Henini ${ }^{4}$ \\ ${ }^{1}$ Mining, Metallurgy and Petroleum Eng. Dep., Faculty of Engineering, Al-Azhar University, \\ Qena- 83513, Egypt. \\ ${ }^{2}$ Nanomaterials Lab., Physics Dep., Faculty of Science, South Valley University, \\ Qena-83523, Egypt. \\ ${ }^{3}$ Egypt Nanotechnology Center (EGNC), Cairo University, El-Sheikh Zayed Campus, \\ Egypt. \\ ${ }^{4}$ School of Physics and Astronomy, Nottingham Nanotechnology and Nanoscience Center, \\ University of Nottingham, Nottingham NG7 2RD, United Kingdom
}

\begin{abstract}
Influence of synthesis temperature and reaction time on structural and optical properties of $\mathrm{ZnO}$ nanoparticles synthesized by hydrothermal method was investigated using X-ray diffraction (XRD), high resolution transmission electron microscopy (HR-TEM), energy-dispersive X-ray (EDX), Fourier transform infrared spectroscopy (FT-IR), and UV-visible and fluorescence spectroscopy. The XRD pattern and HR-TEM images confirmed the presence of crystalline hexagonal wurtzite $\mathrm{ZnO}$ nanoparticles with average crystallite size in the range $30-40 \mathrm{~nm}$. Their energy gap determined by fluorescence was found to depend on the synthesis temperature and reaction time with values in the range 2.90-3.78 eV. Thermal analysis, thermogravimetric (TG) and the differential scanning calorimetry (DSC) were used to study the thermal reactions and weight loss with heat of the prepared $\mathrm{ZnO}$ nanoparticles.
\end{abstract}

\section{Keywords: ZnO nanoparticles; Hydrothermal Synthesis; Reaction time; Energy gap, HR-TEM, Optical properties}

* Corresponding author: dhsw73@gmail.com 


\section{Introduction}

Metal oxide nanoparticles, due to their distinctive properties (optical, electrical, and magnetic), are applied in many areas including energy storage, sensors, optics, coatings, piezoelectric, and biotechnology [1-3]. Zinc oxide nanoparticles are an important class of metal oxide materials, because of their unique physical, electrical, chemical, optical, biological and medical properties. They are suitable for many applications such as solar cells, ultraviolet photodiodes, catalyst, semiconductors, gas sensors, piezoelectric devices, coatings, antibacterial and medical [4-7]. In addition, due to their resistance to the UV-radiation [8] and antimicrobial properties [9] they are used in transparent UV-protection films and as a UV-filter in sunscreens, and in the process of canning food lining, respectively. Recently, $\mathrm{ZnO}$ nanoparticles achieved an effective presence in biomedical and agricultural soils applications [1012].

Many methods have been used to synthesize various $\mathrm{ZnO}$ nanostructures, which include physical vapor deposition, chemical vapor deposition, thermal decomposition and thermal evaporation process [13-15]. These techniques are complex, have a high cost, and require high temperatures. Hydrothermal method is considered as a distinctive alternative method in the fabrication of nanomaterials because it is a process which involves low temperature, simple equipment usage, low cost, and is environmental friendly. Additionally, it has a good control on particles size, structure and morphology of the products. It has been applied to prepare $\mathrm{ZnO}$ nanoparticles and other luminescent materials [16-20].

The aim of the present work was to prepare $\mathrm{ZnO}$ nanoparticles using hydrothermal method and study the influence of reaction time and reaction temperature on their properties. The structure and morphology of the obtained nanostructure product was characterized by using several analysis techniques.

\section{Experimental}

\subsection{Materials}

In $\mathrm{ZnO}$ nanoparticles synthesis, Zinc acetate di-hydrate $\left[\mathrm{Zn}\left(\mathrm{Ch}_{3} \mathrm{COO}\right)_{2} .2 \mathrm{H}_{2} \mathrm{O} 98 \%\right.$ ] and sodium hydroxide [NaOH 98\%] were used. All the commercially purchased materials were used as received without further purification.

\subsection{ZnO nanoparticles synthesis}

Hydrothermal technique has the ability to prepare nanomaterials with high quality and low cost. In this work, the $\mathrm{ZnO}$ nanoparticles were synthesized by a modified hydrothermal method [1,21-22]. The reactions involved in the synthesis process of $\mathrm{ZnO}$ nanoparticles can be described through the following [1]:

$$
\begin{aligned}
& \mathrm{Zn}\left(\mathrm{CH}_{3} \mathrm{COO}\right)_{2} \cdot 2 \mathrm{H}_{2} \mathrm{O}+2 \mathrm{NaOH} \rightarrow \mathrm{Zn}(\mathrm{OH})_{2}+2 \mathrm{CH}_{3} \mathrm{COONa}+2 \mathrm{H}_{2} \mathrm{O} \\
& \mathrm{Zn}(\mathrm{OH})_{2}+2 \mathrm{H}_{2} \mathrm{O}=\mathrm{Zn}^{2+}+2 \mathrm{OH}^{-}+2 \mathrm{H}_{2} \mathrm{O}=\left[\mathrm{Zn}(\mathrm{OH})_{4}\right]^{2} \\
& {\left[\mathrm{Zn}(\mathrm{OH})_{4}\right]^{2} \leftrightarrow \mathrm{ZnO}_{2}^{-2}+2 \mathrm{H}_{2} \mathrm{O}} \\
& \mathrm{ZnO}_{2}^{-2}+2 \mathrm{H}_{2} \mathrm{O} \leftrightarrow \mathrm{ZnO}+2 \mathrm{OH}^{-}
\end{aligned}
$$

The procedure of the formation of $\mathrm{ZnO}$ nanoparticles includes two main steps. Firstly, is the nucleation (generation of $\mathrm{ZnO}$ nuclei), and secondly is the grain growth ( $\mathrm{ZnO}$ crystal growth) [1,21-22]. In equation (1), zinc acetate dissolves into $\mathrm{Zn}(\mathrm{OH})_{2}$ due to 
alkali solution effect. $\mathrm{Zn}(\mathrm{OH})_{2}$ precipitates with the hydrothermal conditions dissolves critical value, which is necessary for the formation of $\mathrm{ZnO}$ crystals (supersaturation degree) (equation 3), $\mathrm{ZnO}$ begins to nucleate and the crystal growth begins (equation 4) $[1,21-22]$.

In typical synthesis, 0.1 Mole (M) of Zinc acetate di-hydrate was dissolved in distilled water and $0.4 \mathrm{M}$ of sodium hydroxide was dissolved in distilled water. The $\mathrm{NaOH}$ solution was poured at a slow rate into the Zinc acetate solution at $75^{\circ} \mathrm{C}$ under continuous stirring. After 2 hours of stirring the mixture was moved to a Teflon lined stainless steel autoclave and maintained at a temperature of $150{ }^{\circ} \mathrm{C}$ for $8 \mathrm{hrs}$. The autoclave was allowed to cool to room temperature naturally. After the completion of the reaction, the produced white precipitate was separated by centrifuge and washed many times by ethanol and distilled water, and then dried in air in an oven at $75^{\circ} \mathrm{C}$ for $6 \mathrm{hrs}$. The same procedure was followed for the preparation of samples at 12, 16, 20 and $24 \mathrm{hrs}$. To study the effect of reaction temperature, the autoclave was maintained at different temperatures $100,125,175$, and $200{ }^{\circ} \mathrm{C}$ for $12 \mathrm{hrs}$.

\subsection{Characterization}

X-ray diffraction patterns were recorded for the prepared nanoparticles to determine the crystal phase and estimate the crystallite size. The crystalline structures of the synthesized powders were analyzed by X-ray diffractometry (X'Pert PRO, PANalytical, Netherlands) using $\mathrm{Cu}-\mathrm{K} \alpha$ radiation in the angular region of $\left(20^{\circ}-70^{\circ}\right)$ at $40 \mathrm{kV}$. The crystallite size (D) and the lattice strain were estimated using the Scherer's equation and Williamson-Hall method. The elemental analysis was performed by energy-dispersive X-ray (EDX) instrument (JEOL, JEMA 2100-Japan) at $10 \mathrm{kV}$. The morphology of the obtained $\mathrm{ZnO}$ nanoparticles was characterized with high resolution transmission electron microscope (HR-TEM), (JEOL, JEMA 2100Japan), performed at $200 \mathrm{kV}$. Fourier transform infra-red (FTIR) spectra was carried out using (FTIR Perkin Elmer-Spectrum One) at range $400-4000 \mathrm{~cm}^{-1}$ with a resolution of $4 \mathrm{~cm}^{-1}$ at room temperature. For the optical measurements, JASCO 6700 UV-VIS-NIR spectrophotometer was used in UV-visible absorption analysis. Fluorescence measurements were taken under ambient conditions and at room temperature by using JASCO 8600 fluorescence spectrophotometer $\left(\lambda_{\mathrm{exc}}=365 \mathrm{~nm}\right)$. Thermal analysis was done using LINSEIS STA PT-1000 to study the thermal stability of $\mathrm{ZnO}$ nanoparticles. Approximately, $25 \mathrm{mg}$ of the samples were used and the heating rate was $10{ }^{\circ} \mathrm{C} / \mathrm{min}$ up to $800{ }^{\circ} \mathrm{C}$.

\section{Results and Discussion}

\subsection{X-ray diffraction (XRD) studies}

Figure $1(\mathrm{a}, \mathrm{b})$ illustrates a typical XRD spectrum of $\mathrm{ZnO}$ nanoparticles synthesized by hydrothermal method under different times 8, 12, 16, 20 and $24 \mathrm{hrs}$ (Fig.1a), and different reaction temperatures 100, 125, 150, 175, and $200{ }^{\circ} \mathrm{C}$ (Fig.1b). The XRD spectra indicate that the $\mathrm{ZnO}$ nanoparticles have a hexagonal structure, with lattice constants $(\mathrm{a}=\mathrm{b}=0.3251 \mathrm{~nm})$ and $(\mathrm{c}=0.5212 \mathrm{~nm})$ as in standard JCPDS data (No. 36-1451). The XRD pattern does not contain any particular peaks other than $\mathrm{ZnO}$ peaks which means that the dominant phase is hexagonal $\mathrm{ZnO}$ nanoparticles. Sharp 
and intense peaks observed from XRD patterns (Figs.1a, b) confirm that the prepared $\mathrm{ZnO}$ nanoparticles is of high crystalline nature with hexagonal phase.

The average crystallite size, $\mathrm{D}$, has been obtained from the main diffraction peak along the (101) plane using the Debye-Scherrer formula [1] as follows:

$$
\mathrm{D}=0.9 \lambda / \beta \cos \theta
$$

where, $\lambda$ is the wavelength of X-ray used (1.54060 $\AA$ ), $\boldsymbol{\beta}$ is the angular peak width at half maximum in radians and $\boldsymbol{\theta}$ is Bragg's diffraction angle. From the recorded XRD pattern, the synthesized $\mathrm{ZnO}$ nanoparticles are listed as wurtzite hexagonal closely packed structure and its lattice constants a and c were determined from the following equation using the interplanar distance $\mathrm{d}$ and (hkl) values of the XRD profile [23],

$$
\frac{1}{d^{2}}=\frac{4}{3}\left[\frac{h^{2}+h k+l^{2}}{a^{2}}\right]+\frac{l^{2}}{c^{2}}
$$

Table 1 shows the calculated lattice parameters, which are matched to those available in standard JCPDS data (No. 36-1451). To estimate the crystallite size and the lattice strain, an inspection of the shape of the diffraction peaks was performed using Williamson-Hall (WH) method (Equation 7). WH calculations procedure is carried out for every peak obtained in the XRD spectra of the $\mathrm{ZnO}$ nanoparticles. The full width at half maximum (FWHM), $\boldsymbol{\beta}$, is related to the crystallite size, $\mathbf{D}$, and the strain, $\boldsymbol{\varepsilon}$, by equation 7 :

$$
\beta^{*}=d^{*} \varepsilon+1 / D
$$

where $\boldsymbol{\beta}^{*}=\boldsymbol{\beta} \cos \boldsymbol{\theta} / \boldsymbol{\lambda}$ and $\mathbf{d}^{*}=\mathbf{4} \sin \boldsymbol{\theta} / \boldsymbol{\lambda} ; \theta$ is the Bragg angle and $\boldsymbol{\lambda}$ is the wavelength used. From Eq. (7), the intercept and the slope of the plot of $\boldsymbol{\beta}^{*}$ against $\mathbf{d}^{*}$ give $\mathbf{1 / D}$ and the strain [24-25], respectively. Table 1 shows crystallite size values for the prepared samples estimated by Scherer and Williamson-Hall methods. From the XRD calculations, it is obvious that the average crystallite size slightly increases with the increase of the reaction time and synthesis temperature (see Fig. 2a, b). This may be due to increasing of nucleation and growth rate of nanoparticles [23]. From table 1, it is clear that the crystallite size calculated from XRD data using Debye-Scherrer equation is smaller than crystallite size determined from Williamson-Hall method. This may be due to the fact that the Scherrer method actually measures the coherence length of the X-rays, any crystal imperfections will cause the calculated size to be smaller than the true size but in WH method the microstrain effect was taken into consideration [26].

The dislocation density (concentration of defects and vacancies in the crystal), $\mathbf{S}$, can be determined from the following equation by using the crystallite size (D) [23]:

$$
S=1 / \mathbf{D}^{2}
$$

From Table 1, it can be seen that $\mathbf{S}$ changes with different values of time and temperature, which means that the lattice imperfection decreases with particle size. Also, the micro-strain of the samples changes with time and temperature, which may be attributed to the change in microstructure, size, shape and defects of the particles [27].

\subsection{Energy-dispersive X-Ray (EDX)}


Figure 3 (a, b) shows the EDX spectrum of $\mathrm{ZnO}$ nanoparticles synthesized by spectra were obtained for all the prepared samples, only two spectra are shown here $\left(\mathrm{S}_{1}\right.$ and $S_{8}$ ). The strong peaks shown in the spectra, referred to zinc and oxygen elements, indicate that the synthesized nanoparticles have $\mathrm{Zn}$ and $\mathrm{O}$ elements only.

\subsection{Transmission electron microscope analysis}

HR-TEM was carried out to investigate the shape and size of the synthesized $\mathrm{ZnO}$ nanoparticles. Figure $4\left(\mathrm{~S}_{1}-\mathrm{S}_{10}\right)$ shows the HR-TEM images of prepared $\mathrm{ZnO}$ nanoparticles with different reaction times $8,12,16,20$ and $24 \mathrm{hrs}$ and reaction temperatures 100, 125, 150, 175, and $200{ }^{\circ} \mathrm{C}$. The reaction time and synthesis temperature affect the shape and size of the obtained $\mathrm{ZnO}$ nanoparticles. The particles with spherical-like shape were observed in $S_{1}$ and $S_{6}$ only. With increasing the reaction time and temperature spherical-like and rods shapes of $\mathrm{ZnO}$ nanoparticles were obtained due to the increase of the growth rate. As the reaction time and temperature increased, nearly all the $\mathrm{ZnO}$ nanoparticles appeared in clusters of nanorods shape due to smaller nanoparticles coalescing and forming larger particles, i.e. clusters. From the HR-TEM images the average size of the $\mathrm{ZnO}$ nanoparticles is in the range of 30-40 nm, which agree with the size determined from XRD data.

\subsection{Fourier transform infra-red (FT-IR) analysis}

Figures 5 (a) and 5 (b) display results of FT-IR analysis for prepared $\mathrm{ZnO}$ nanoparticles at different times and temperatures, respectively. A group of absorption peaks observed in the range of 4,000 to $400 \mathrm{~cm}^{-1}$ represents the vibration modes of contaminations such as hydroxyl, carboxyl found in the prepared nanoparticles. The absorption bands at $\left(3433-3413 \mathrm{~cm}^{-1}\right)$ represent $\mathrm{O}-\mathrm{H}$ stretching vibration. Peaks recorded between $\left(1,626\right.$ and $\left.1,581 \mathrm{~cm}^{-1}\right)$ are probably from $\mathrm{C}=\mathrm{O}$ band. The absorption peaks at $\left(1,410-1,435 \mathrm{~cm}^{-1}\right)$ represent the carboxylate group $\left(\mathrm{COO}^{-}\right)$. The peaks around $\left(1,021-1,028 \mathrm{~cm}^{-1}\right)$ confirm the stretching vibration of $\mathrm{C}-\mathrm{O}$ attributed to zinc acetate. In the infra-red region, characteristic $\mathrm{Zn}-\mathrm{O}$ stretching mode was found between $\left(418\right.$ and $\left.571 \mathrm{~cm}^{-1}\right)$. The difference in wavenumber may be attributed to the difference in particle sizes of prepared samples [7,23,28-29].

\subsection{Optical properties of $\mathrm{ZnO}$ nanoparticles}

Figures 6 (a) and 6 (b) show the optical absorption and transmittance spectra of the prepared samples at near normal incidence over a spectral ranging between 200 and $800 \mathrm{~nm}$ for different times and temperatures, respectively. The direct optical band gap with direct transition can be calculated using the relation:

$$
\boldsymbol{\alpha h} \gamma=\mathbf{B}(\mathbf{h} \gamma-\mathbf{E g})^{1 / 2}
$$

where $\mathbf{h} \boldsymbol{\gamma}$ is the photon energy and $\mathbf{B}$ is a constant that depends on the transition probability, $\boldsymbol{\alpha}$ is the absorption coefficient and $\mathbf{E}_{\mathbf{g}}$ is the optical band gap. As shown in Figure 7 (a, b) the energy gap $\left(\mathbf{E}_{\mathbf{g}}\right)$ can be estimated from the plot $\mathbf{h} \gamma$ against $(\boldsymbol{\alpha} \mathbf{h} \gamma)^{2}$. The values of $\mathbf{E}_{\mathbf{g}}$ are in the range (2.90-3.62 eV) and depend the reaction times and reaction temperatures (Table 2). These obtained values are different from that of the bulk $\mathrm{ZnO}(3.37 \mathrm{eV})$. This blue shift may be attributed to quantum confinement effects in the prepared zinc oxide samples [20,23]. 
From Fig.7, it can be noticed that with increasing the reaction time and reaction This confirms that the above behavior may be due to increasing of nucleation and growth rate of nanoparticles [23].

\subsection{Fluorescence Spectra of ZnO Nanoparticles}

Figures 8(a) and 8(b) show fluorescence spectra of $\mathrm{ZnO}$ nanoparticles synthesized under different reaction times and temperatures, respectively. Each curve reveals that the PL intensity decreases with reaction times and temperatures. The observed dominant narrow UV emission band peak at $417 \mathrm{~nm}$ originates from the near-bandedge transition and its intensity decreases with increasing particle size of $\mathrm{ZnO}$ nanoparticles. The tail-band violet emission at $445 \mathrm{~nm}$ is attributed to the presence of zinc interstitials $\left(\mathrm{Zn}_{\mathrm{i}}\right)$. Exciton recombination between the electrons at the zinc interstitials and valence band holes leads to this violet emission. This type of violet emission band was also observed by others [23,30]. The broad-band green emission at $530 \mathrm{~nm}$ is assigned to the recombination of electrons trapped at vacancy defects [3133]. The fluorescence spectrum confirms that the type of emissions from the $\mathrm{ZnO}$ nanoparticles, whether UV (or) violet is affected by the time and temperature of the reaction. In addition, the violet and green bands confirm that the samples contain $\mathrm{ZnO}$ nanoparticles [30,34-35].

\subsection{Thermal analysis spectra}

Figure $9(\mathrm{a}, \mathrm{b})$ shows the thermogravimetric (TG) analysis of $\mathrm{ZnO}$ nanoparticles. From the figure, it can be seen that there is no significant weight loss observed for all samples (approximately 10\%). This may be due to the evaporation of water and the removal and decomposition of organic groups found in the samples during the hydrothermally synthesis [36-39]. Furthermore, no significant loss of weight was observed from the samples above $750{ }^{\circ} \mathrm{C}$.

Figures 10(a) and 10(b) show the differential scanning calorimetry (DSC) of $\mathrm{ZnO}$ nanoparticles under different reaction times and temperatures, respectively. Two peaks are observed, the first one occurs at around $150{ }^{\circ} \mathrm{C}$ and is weak. This peak can be attributed to an activation energy involving an endothermic reaction. The second peak around $400{ }^{\circ} \mathrm{C}$ is a broad, which suggests an exothermic reaction that may be due to the burn-out of organic composition. It is worth pointing out that both peaks are due to change of phases at those temperatures [36-39].

\section{Conclusions}

$\mathrm{ZnO}$ nanoparticles have been synthesized by using modified hydrothermal method at different reaction times and synthesis temperatures. The results confirmed that reaction time and synthesis temperature have an influence in the structure and optical properties of $\mathrm{ZnO}$ nanoparticles. XRD studies established the presence of the wurtzite hexagonal structure, and showed that the average crystallite size slightly increases with the increase of the reaction time and synthesis temperature. HR-TEM images showed that the average size of the $\mathrm{ZnO}$ nanoparticles is in the range of $30-40 \mathrm{~nm}$, which is in a good agreement with the size determined by XRD. UV-Vis spectra indicate that with increasing the reaction time and reaction temperature, the band gap value decreases due to the increase of the crystallite size. The fluorescence spectra 
confirm that the type of emissions from the $\mathrm{ZnO}$ nanoparticles, is affected by the time and temperature of the reaction. $\mathrm{TG}$ analysis of the $\mathrm{ZnO}$ nanoparticles showed that no significant loss of weight was observed above $750 \mathrm{oC}$ for all prepared samples. DSC of $\mathrm{ZnO}$ samples under different times and temperatures indicates endothermic reactions and exothermic reactions which are due to change of phases at those temperatures.

\section{ACKNOWLEDGEMENT}

The authors would like to express their gratitude to Al-Azhar University and South Valley University for providing administrative and technical support.

\section{References}

1. A.M.O. Dalia, A.M. Mustafa, Synthesis and Characterization of Zinc Oxide Nanoparticles using Zinc Acetate Dihydrate and Soium Hydroxide, Journal of Nanoscience and Nanoengineering 1 (2015) 248-251.

2. A. Benazir, K. Gomathi, S. Aram. Structural and Optical Properties of Zn1-xNixO Nanoparticles Synthesized by Co-precipitation Method, J. Environ. Nanotechnol. 6 (2017) 39-43.

3. K.P. Kamal, G. Dambaru, A. Venugopal, V.M.A. Mohan, P. Ganngam, L.P. Narasimham, K.S. Hrushi, B.P. Brahma, Green Synthesized Zinc Oxide (ZnO) Nanoparticles Induce Oxidative Stress and DNA Damage in Lathyrus sativus L. Root Bioassay System, Antioxidants 6 (2017) 35-51.

4. A.K. Barve, S.M. Gadegone, M.R. Lanjewar, R.b. Lanjewar, Synthesis of ZnO nanomaterial by Precipitation Method and its Characterization, International Journal of Chemical and Physical Sciences 4, (2015) 432-439.

5. S. Sabita, C.B. Subash, P.S. Shankar, P.J. Leela, Synthesis and study of zinc oxide nanoparticles for dye sensitized solar cell, Research Journal of Physical Sciences, 5 (2017) 6-10.

6. R.A. Zargar, M. Arora, Synthesis and Characterization of $\mathrm{ZnO}$ Nanoparticles for Biomedical Applications, Glob J Nanomed, 2 (2017) 1-3.

7. K. Zheng, K. Zidek, M. Abdellah, P. Chabera, M.S. Abd El-sadek, T. Pullerits, Effect of metal oxide morphology on electron injection from CdSe quantum dots to ZnO, Applied Physics Letters 102 (2013) 163119-1 - 163119-5.

8. M. Vaseem, A. Umar, Y.B. Hanh, ZnO nanoparticles: Growth, properties, and applications. In: A.Ummer, Y.B. Hanh (Eds), Metal Oxide Nanostructures and Their Applications, 5 American Scientific Publishers, Los Angeles, CA, USA, (2010) 1-36.

9. Y. Xie, Y. He, P.L. Irwin, T. Jin, X. Shi, Antibacterial activity and mechanism of action of zinc oxide nanoparticles against Campylobacter jejuni, Appl. Environ. Microbiol. 77 (2001) 2325-2331.

10. J.W. Rasmussen, E. Martinez, P. Louka, G. Denise, D.G. Wingett, Zinc oxide nanoparticles for selective destruction of tumor cells and potential for drug delivery applications, Expert Opin. Drug Deliv, 7 (2010) 1063-1077.

11. J.L. Watson, T. Fang, C.O. Dimkpa, D.W. Britt, J.E. McLean, A. Jacobson, A.J. Anderson, The phytotoxicity of $\mathrm{ZnO}$ nanoparticles on wheat varies with soil properties, Biometals 28 (2015) 101-112.

12. H. Ma, P.L. Williams, S.A. Diamond, Ecotoxicity of manufactured $\mathrm{ZnO}$ nanoparticles-A review, Environ. Pollut. 172 (2013) 76-85. 
13. Z. An-Qi, Z. Lu, S. Li, Q. Dong-Jin, C. Meng, Morphology-controllable synthesis of $\mathrm{ZnO}$ nano-microstructures by a solvothermal process in ethanol solution Cryst. Res. Technol. 48 (2013) 947-955.

14. E. R. Shaaban, A. M. A. Mostafa, H. Shokry Hassan, M.S. Abd El-Sadek, Gehan Y. Mohamed, I. Sharaf, Effect of $\gamma$-irradiation on Structural and Optical Ellipsometry Parameters of $\mathrm{ZnO}$ Nanocrystalline, Int. J. Thin Film Sci. Tec. 3 (2014) 129-141.

15. S.D. Lee, S.H. Nam, M.H. Kim, J.H. Boo, Synthesis and photocatalytic property of $\mathrm{ZnO}$ nanoparticles prepared by spray-pyrolysis method, Physics Procedia 32 (2012) 320-326.

16. H.P. Suryawanshi, S.G. Bachhav, D.R. Patil, Hydrothermal Synthesis of Zinc Oxide and Its Photocatalytic Effect, IJCPS 4 (2015) 483-486

17. B. Sunandan, D. Joydeep, Hydrothermal growth of $\mathrm{ZnO}$ nanostructures, Sci. Technol.Adv. Mater. 10 (2009) 1-18.

18. A.S. Nehal, E.K. Maged, M.I. Ebtisam, Synthesis and Characterization of ZnO Nanotubes by Hydrothermal Method, IJSRP, 5 (2015) 1-4.

19. A.R. Reddy, A.N. Mallika, K.S. Babu, K.V. Reddy, Hydrothermal synthesis and characterization of $\mathrm{ZnO}$ nanocrystals, International Journal of Mining, Metallurgy \& Mechanical Engineering, 3 (2015) 52-55.

20. S.N. Shaha, I.S. Alib, A.S. Rizwan, M. Naeema, B. Yasmeen, S.A. Rehan, S.R. Masood, K. Yousuf, K. S. Sikander, Synthesis and Characterization of Zinc Oxide Nanoparticles for Antibacterial Applications, Journal of Basic \& Applied Sciences, 12 (2016) 205-210.

21. K.P. Saroj, A novel chemical approach to fabricate $\mathrm{ZnO}$ Nanostructure, $\mathrm{PhD}$ thesis, Indian Institute of Technology Kharagpur (2008).

22. K. Venkateswarlu, D. Sreekanth, M. Sandhyarani, V. Muthupandi, A. C. Bose, N. Rameshbabu, X-Ray Peak Profile Analysis of Nanostructured Hydroxyapatite and Fluorapatite, International Journal of Bioscience, 2 (2012) 389-393.

23. C.M. Jay, M. Sathya, K. Pushpanathan, Effect of $\mathrm{pH}$ on Crystal Size and Photoluminescence Property of $\mathrm{ZnO}$ Nanoparticles Prepared by Chemical Precipitation Method, Acta Metall. Sin. (Engl. Lett.), 28 (2015) 394-404.

24. K.G. Williamson, H.W. Hall, X-ray broadening from field aluminium and wolfram, Acta Metall. 1 (1953) 1-22.

25. S.K.V. Sesha, K.P. Venkateswara, X-ray Peak Broadening Analysis and Optical Studies of $\mathrm{ZnO}$ Nanoparticles Derived by Surfactant Assisted Combustion Synthesis, Journal of Nano- and Electronic Physics 5 (2013) 02026-1 - 02026-6.

26. J. Markmann, V. Yamakov, Weissemu“ller. Validating grain size analysis from X-ray line broadening: A virtual experiment J. Scr. Mater. 59 (2008) 15-18.

27. A. Jagannatha Reddy, M.K. Kokila, H. Nagabhushan, R.P.S. Chakradhar, C. Shivakumar, J.L. Rao, B.M. Nagabhushan, Structural, optical and EPR studies on $\mathrm{ZnO}: \mathrm{Cu}$ nanopowders prepared via low temperature solution combustion synthesis, Journal of Alloys and Compounds 509 (2011) 5349-5355.

28. D.M. Fernandes, R. Silva, A.A.W. Hechenleitner, E. Radovanovic, M. MAC, E.A.G. Pineda, Synthesis and characterization of $\mathrm{ZnO}, \mathrm{CuO}$ and a mixed $\mathrm{Zn}$ and Cu oxide, Mater. Chem. Phys. 115 (2009) 110-115.

29. F. Ahmed, S. Kumar, N. Arshi, M.S. Anwar, B.H. Koo, C.G. Lee, Rapid and Cost Effective Synthesis of Zno Nanorods Using Microwave Irradiation Technique, Funct. Mater. Lett. 4 (2011) 1-5. 
30. C.H. Ahn, Y.Y. Kim, D.C. Kim, S.K. Mohanta, H.K. Cho, A comparative analysis of deep level emission in $\mathrm{ZnO}$ layers deposited by various methods, J. Appl. Phys. 105 (2009) 013502-1 - 013502-5.

31. S. Fujita, K. Matsuura, Inclusion of Zinc Oxide Nanoparticles into Virus-Like Peptide Nanocapsules Self-Assembled from Viral $\beta$-Annulus Peptide, Nanomaterials, 4 (2014) 778-791.

32. Z.W. Liang, X.A. Yu, B.F. Lei, P.Y. Liu, W.J. Mai, Novel blue-violet photoluminescence from sputtered $\mathrm{ZnO}$ thin films, J. Alloys Compd, 509 (2011) 5437-5440.

33. Y. $\mathrm{Hu}, \mathrm{H} . J$. Chen, Preparation and characterization of nanocrystalline $\mathrm{ZnO}$ particles from a hydrothermal process, J. Nanopart. Res, 10 (2008) 401-407.

34. C. Aydın, M.S. Abd El-sadek, Kaibo Zheng, I.S. Yahia, F. Yakuphanoglu, Synthesis, diffused reflectance and electrical properties of nanocrystalline $\mathrm{Fe}$ doped $\mathrm{ZnO}$ via sol-gel calcination technique, Optics \& Laser Technology 48 (2013) 447-452.

35. R. Bekkari, L. laânab, D. Boyer, R. Mahiou, B. Jaber, Influence of the sol gel synthesis parameters on the photoluminescence properties of $\mathrm{ZnO}$ nanoparticles, Materials Science in Semiconductor Processing 71 (2017) 181-187.

36. J.N. Hasnidawani, H.N. Azlina, H. Norita, N.N. Bonnia, S. Ratim, E.S. Ali, Synthesis of ZnO Nanostructures Using Sol-Gel, Procedia Chemistry 19 (2016) 211-216.

37. S. Bagheri, K.G. Chandrappa, S. B. Abd Hamid, Facile synthesis of nano-sized ZnO by direct precipitation method, Der Pharma Chemica, 5 (2013) 265-270.

38. N.A. Salahuddin, M. El-Kemary, E.M. Ibrahim, Synthesis and Characterization of ZnO Nanoparticles via Precipitation Method: Effect of Annealing Temperature on Particle Size, Nanoscience and Nanotechnology, 5 (2015) 82-88.

39. Sarunya Klubnuan, Pongsaton Amornpitoksuk, Sumetha Suwanboon, Structural, optical and photocatalytic properties of $\mathrm{MgO} / \mathrm{ZnO}$ nanocomposites prepared by a hydrothermal method, Materials Science in Semiconductor Processing 39 (2015) 515-520. 


\section{Figures}

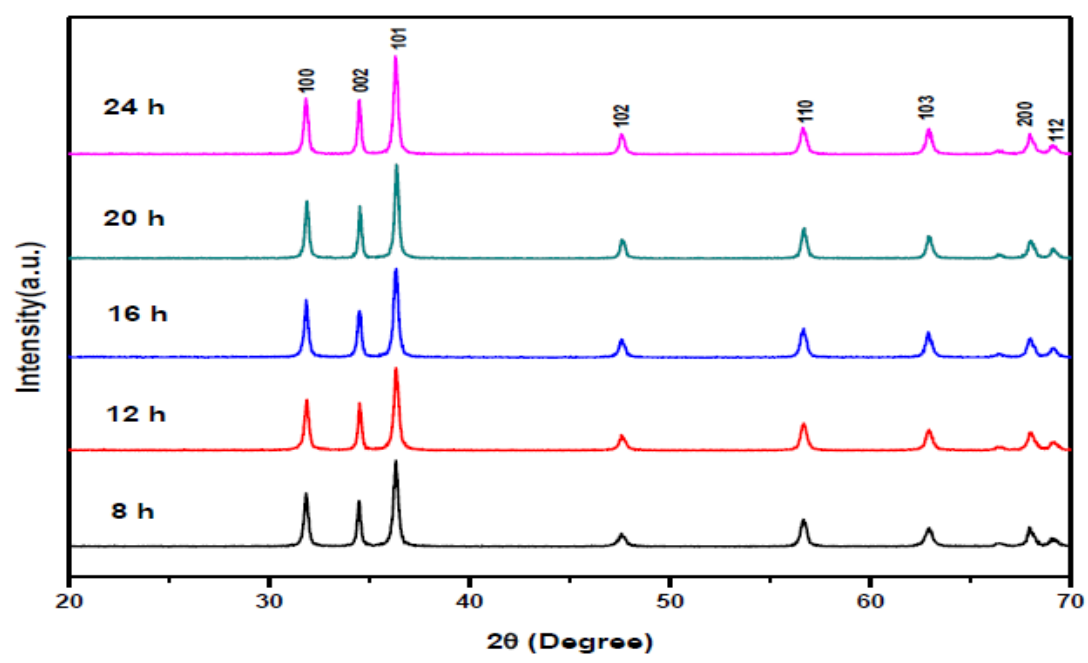

Fig. 1a XRD spectrum of $\mathrm{ZnO}$ nanoparticles under different reaction times 8, 12, 16, 20 and 24 hrs.

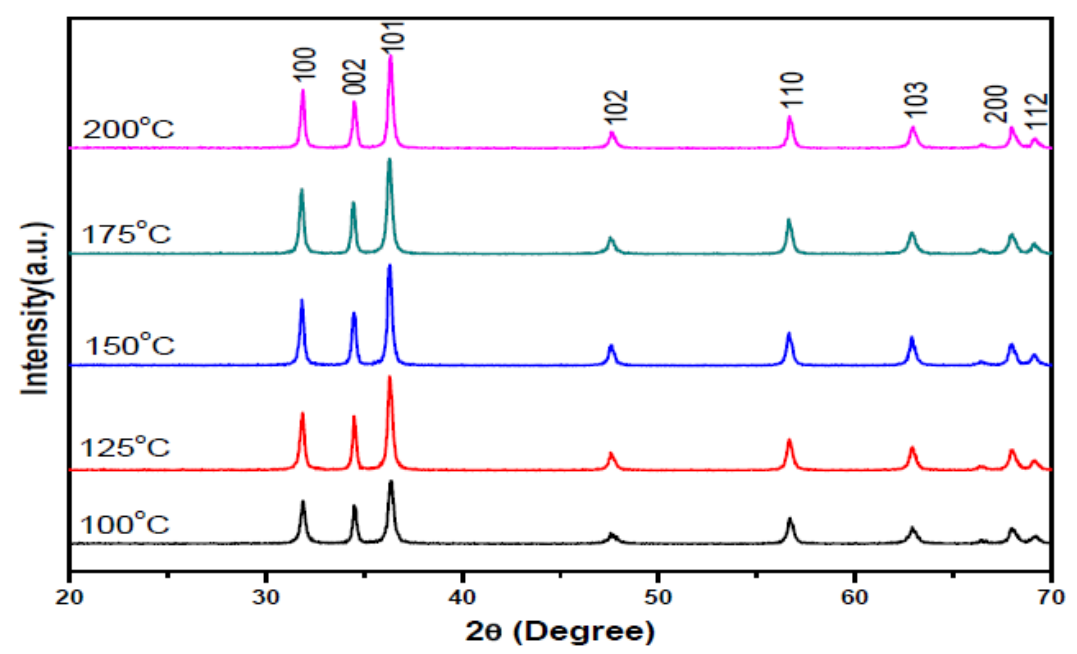

Fig.1b XRD spectrum of $\mathrm{ZnO}$ nanoparticles under different synthesis temperatures $100,125,150,175$, and $200{ }^{\circ} \mathrm{C}$.
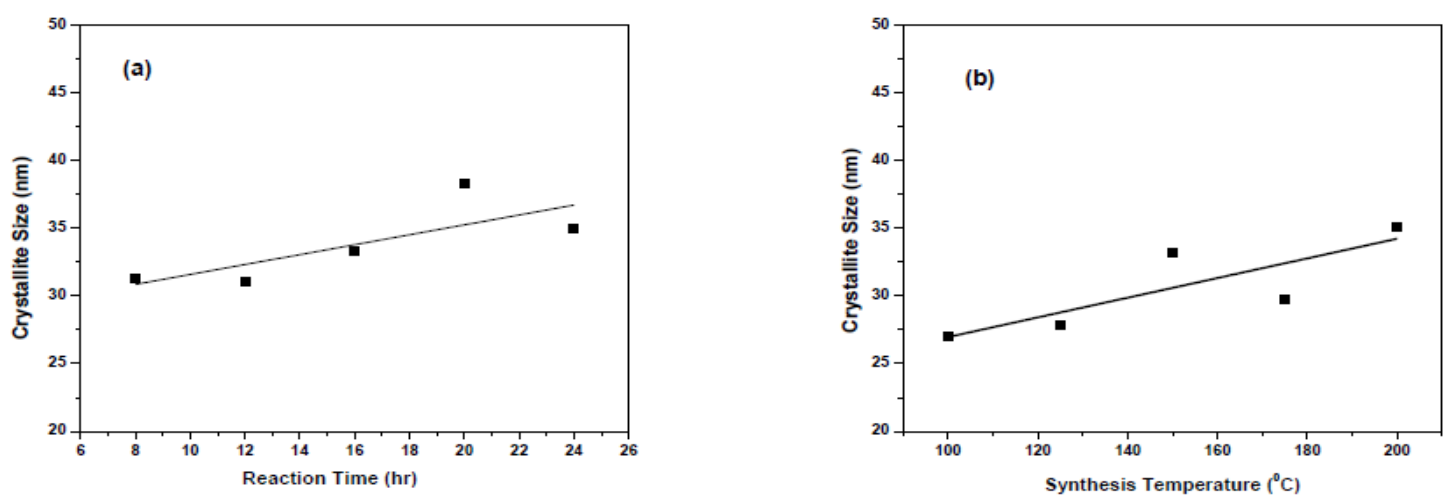

Fig. 2: Crystallite size as a function of (a) reaction time and (b) synthesis temperature. 

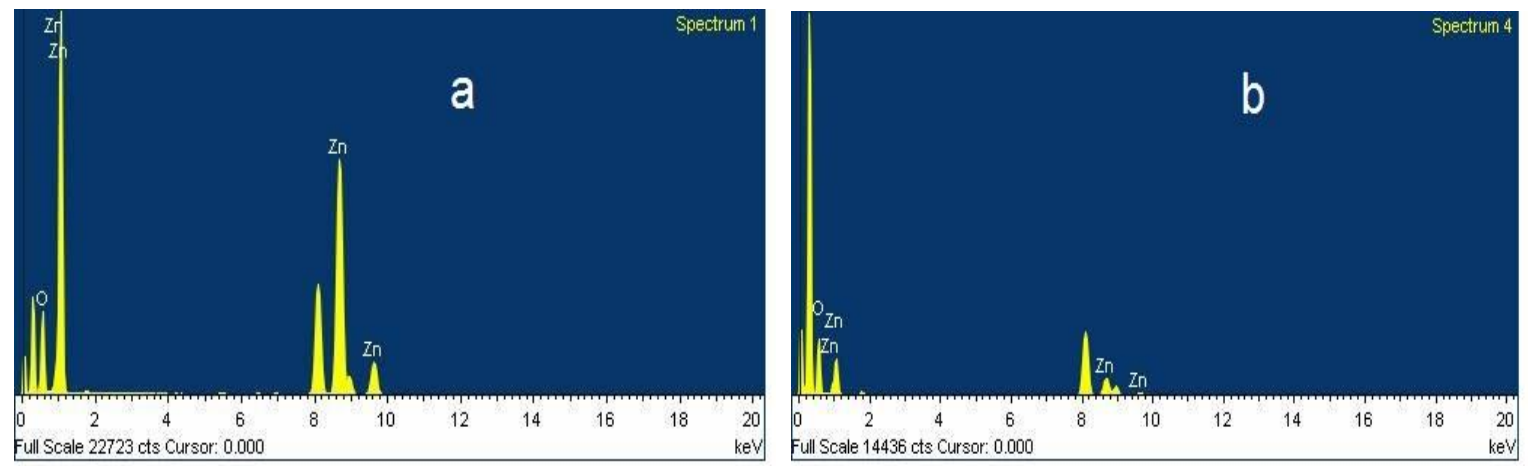

Fig.3 EDX spectra of $\mathrm{ZnO}$ nanoparticles prepared at (a) 8 hours and (b) $150{ }^{\circ} \mathrm{C}$.
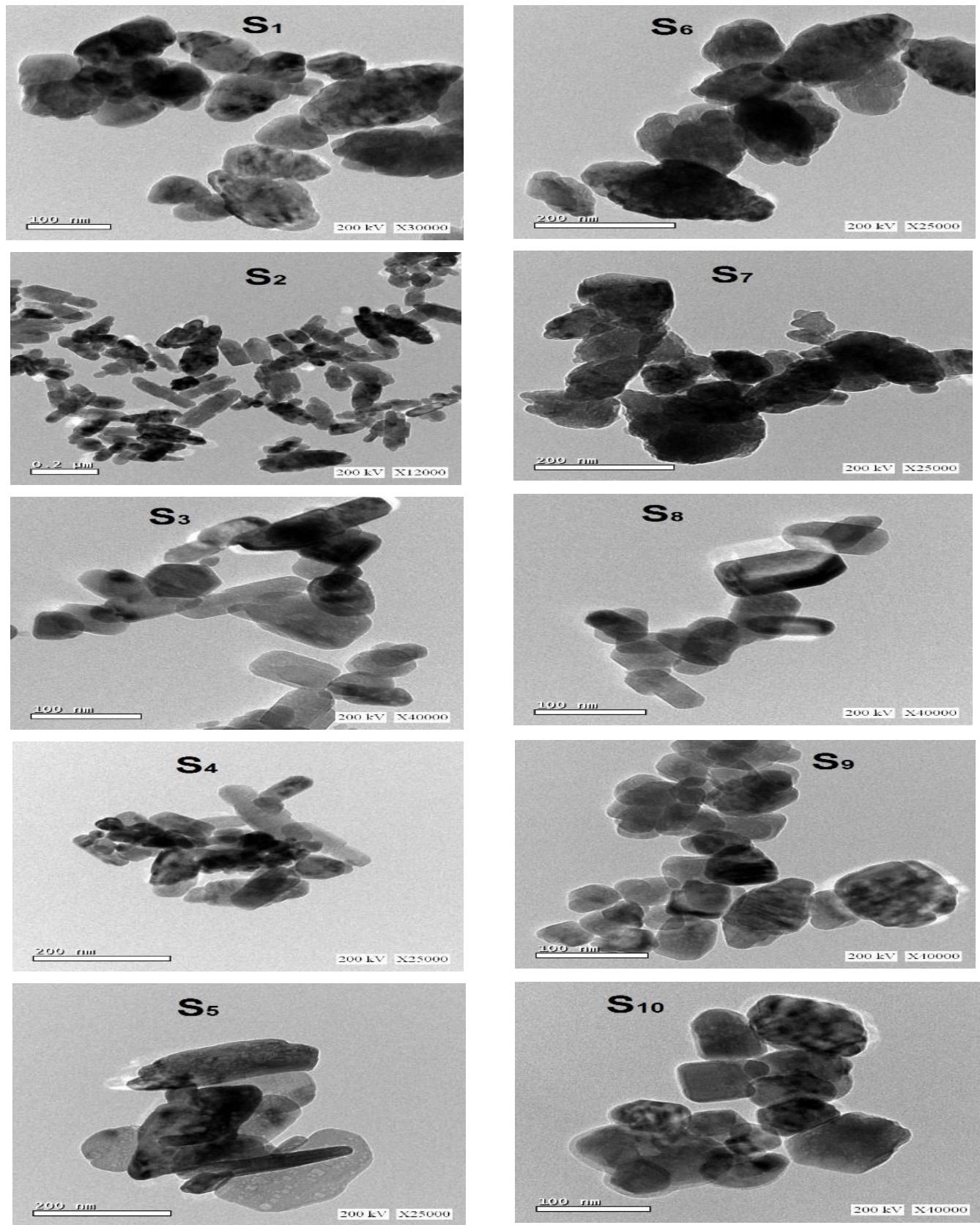

Fig. 4 HR-TEM images of prepared $\mathrm{ZnO}$ nanoparticles synthesized at various reaction times $\left(\mathbf{S}_{1}-\mathbf{S}_{5}\right)$ and various temperatures $\left(\mathbf{S}_{6}-\mathbf{S}_{10}\right)$. 


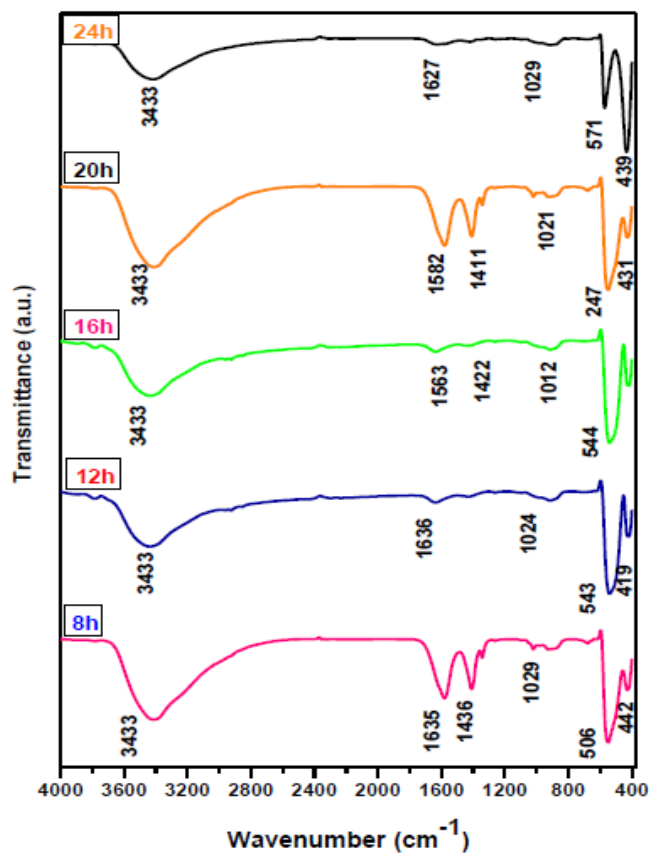

a)

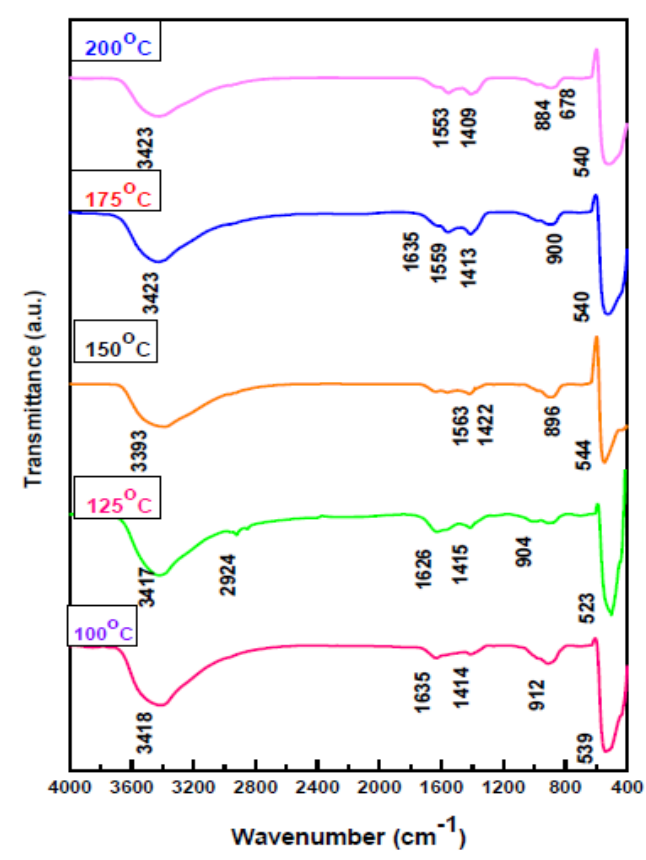

b)

Fig. 5 FT-IR spectra of ZnO nanoparticles synthesized at (a) various reaction times and (b) various temperatures.
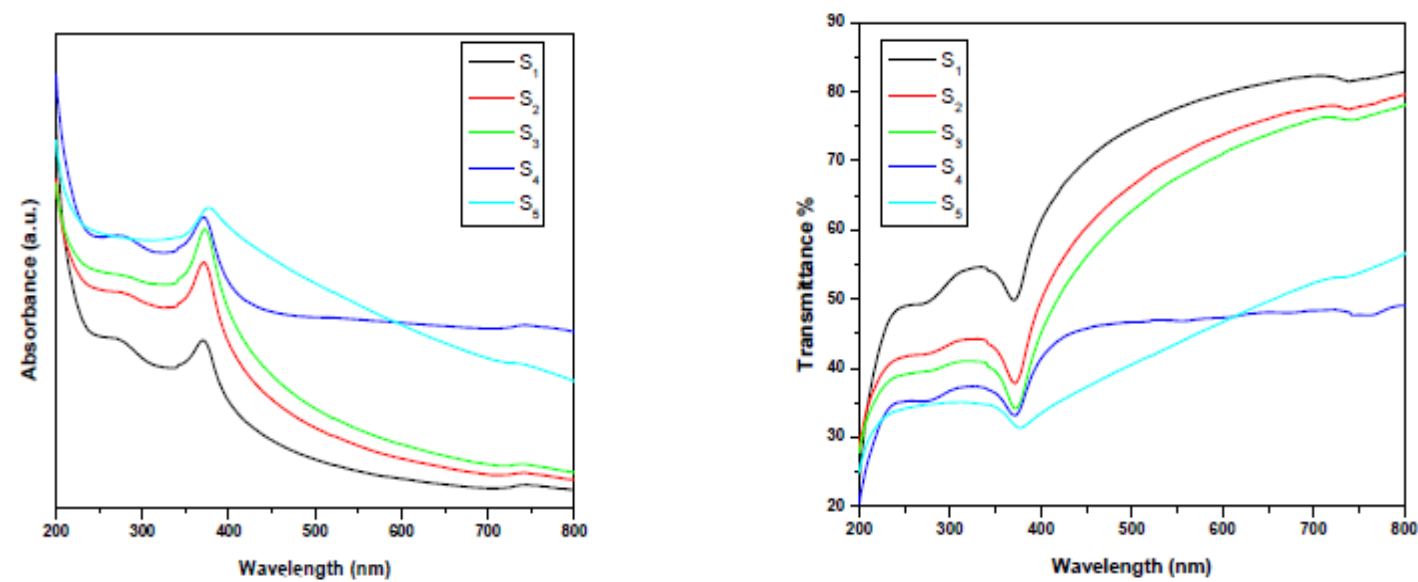

Fig. 6a Absorbance and transmittance spectra of $\mathrm{ZnO}$ nanoparticles synthesized at different times. 

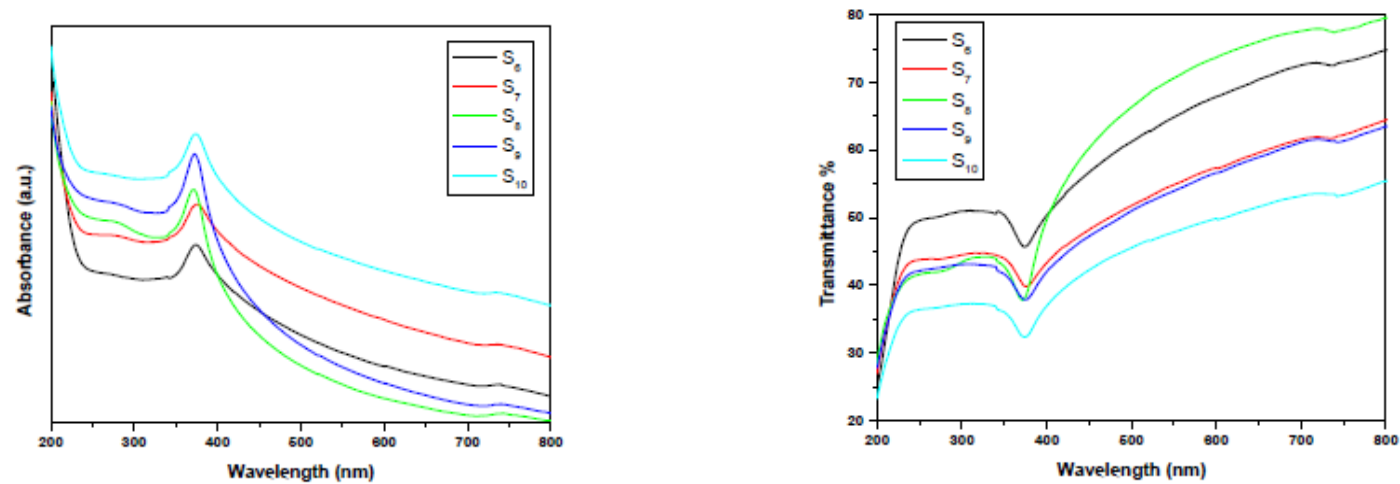

Fig. 6b Absorbance and transmittance spectra of $\mathrm{ZnO}$ nanoparticles synthesized at different temperatures.

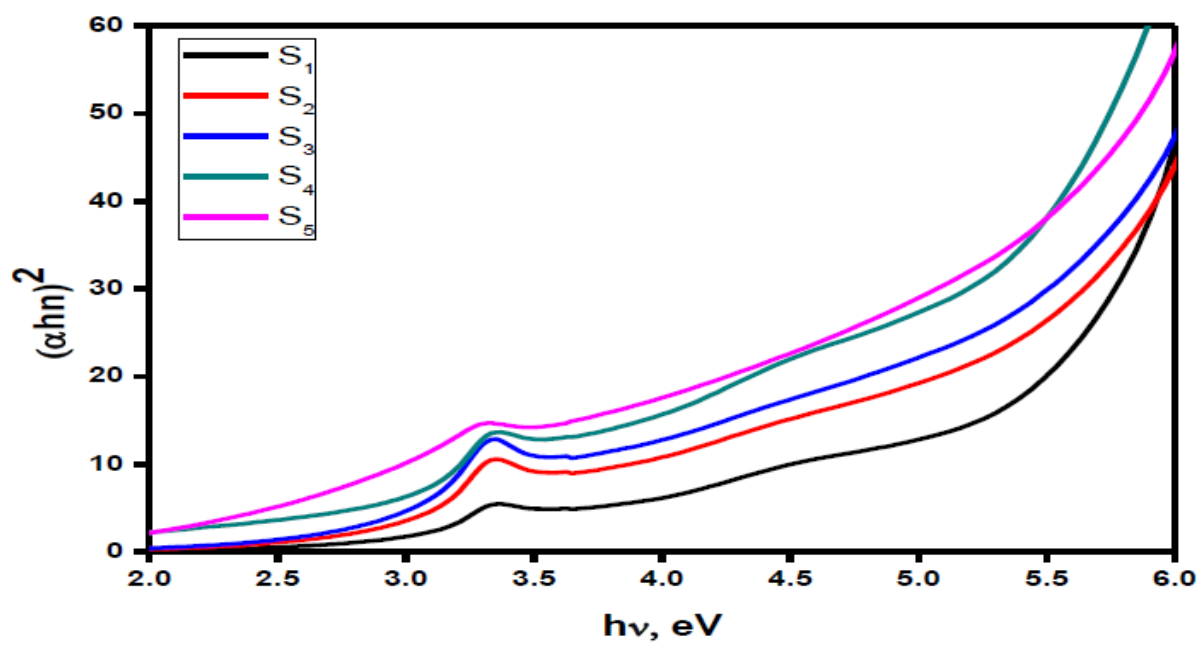

Fig. 7a Plots of hy against $(\alpha \mathrm{h} \gamma)^{2}$ of $\mathrm{ZnO}$ nanoparticles synthesized at different reaction times.

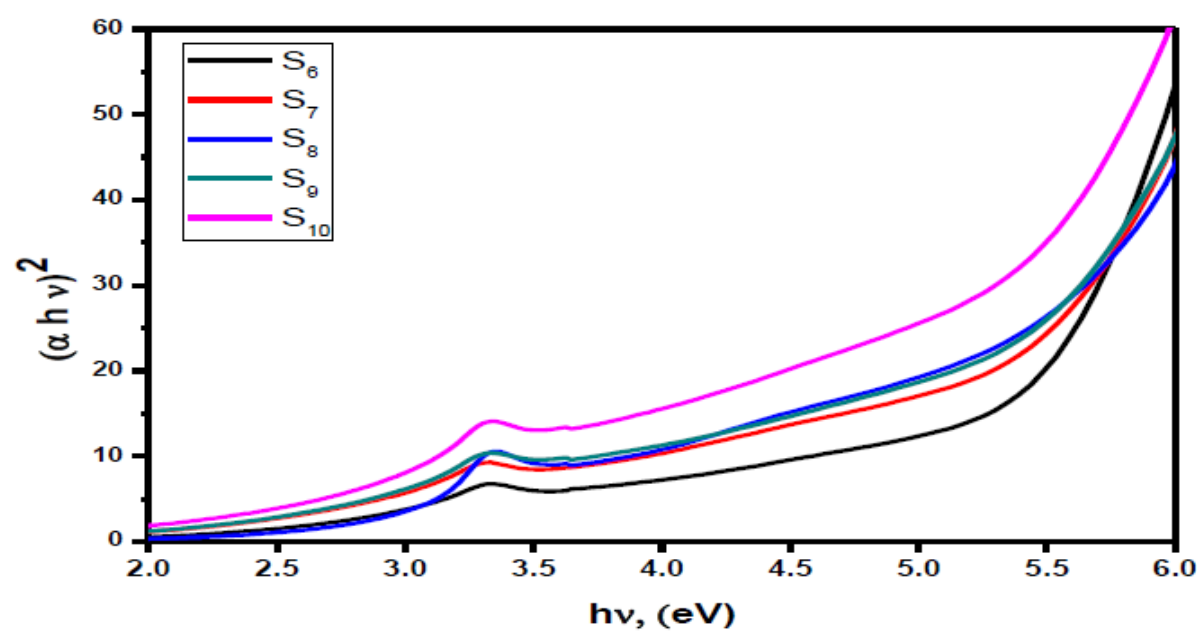

Fig. 7b Plots of hy against $(\alpha h \gamma)^{2}$ of $\mathrm{ZnO}$ nanoparticles synthesized at different temperatures. 


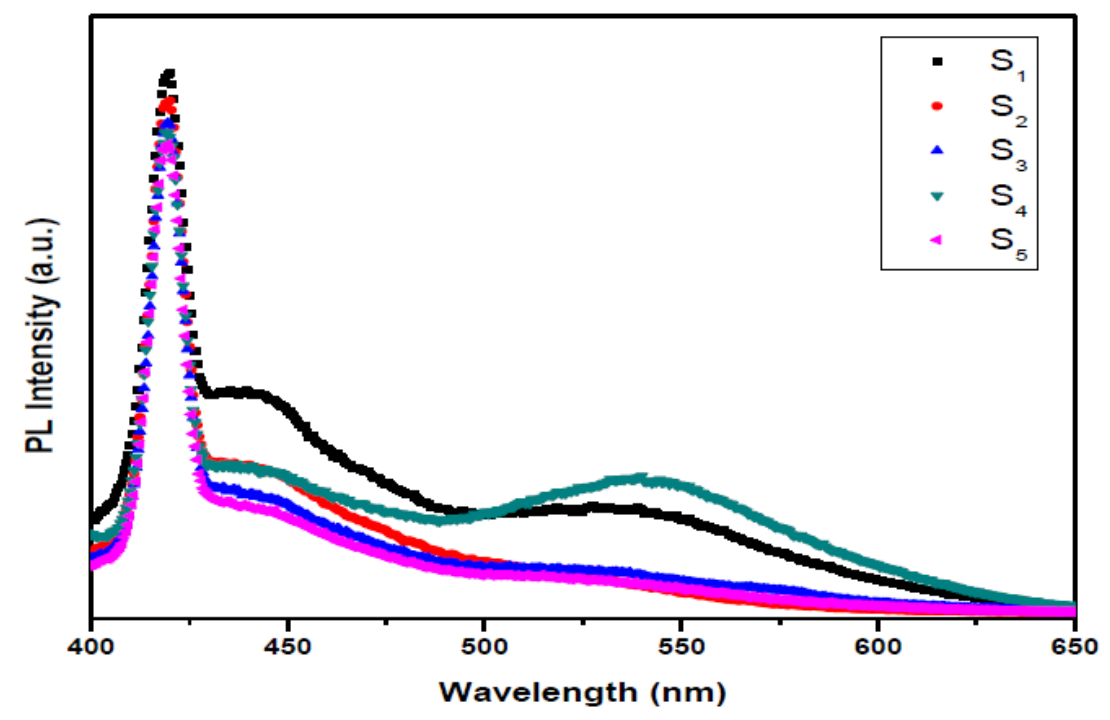

Fig. 8a Fluorescence spectra of the $\mathrm{ZnO}$ nanoparticles synthesized at different times.

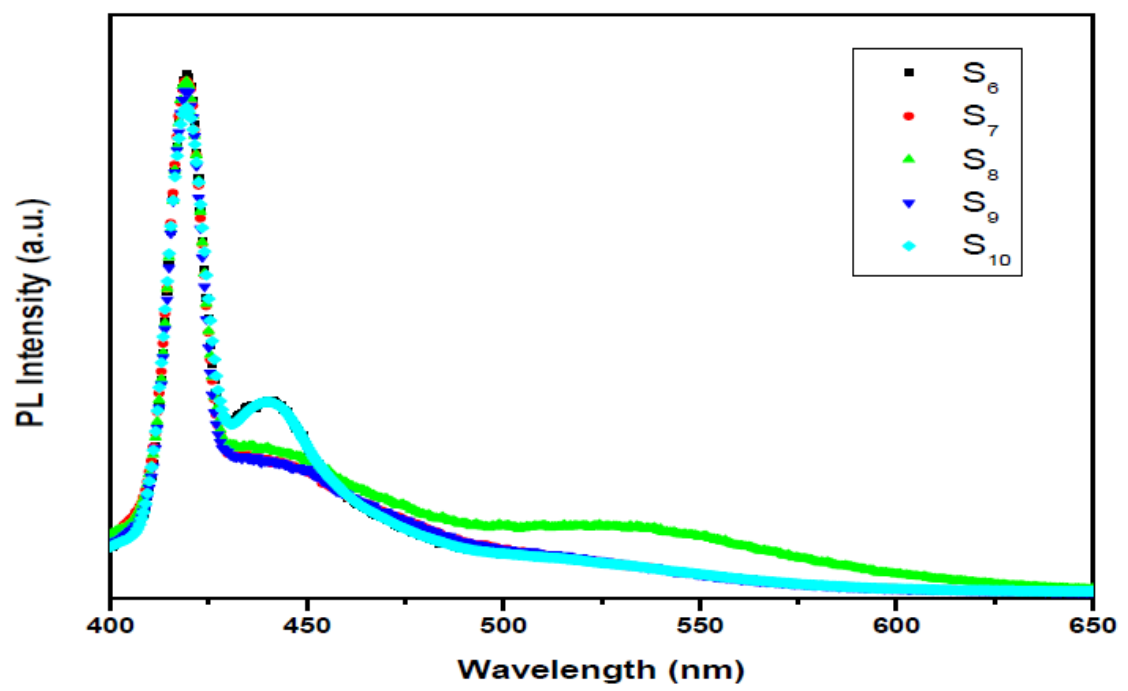

Fig. 8b Fluorescence spectra of the $\mathrm{ZnO}$ nanoparticles synthesized at different temperatures. 


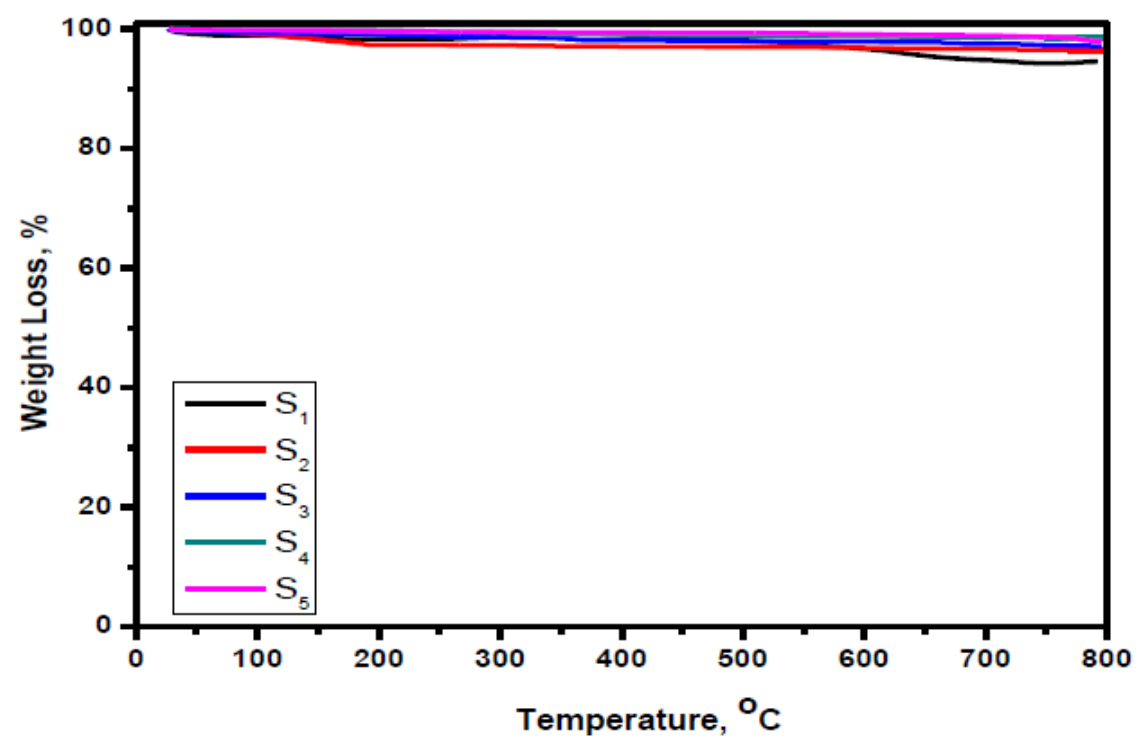

Fig. 9a TG curves of $\mathrm{ZnO}$ nanoparticles synthesized at different times.

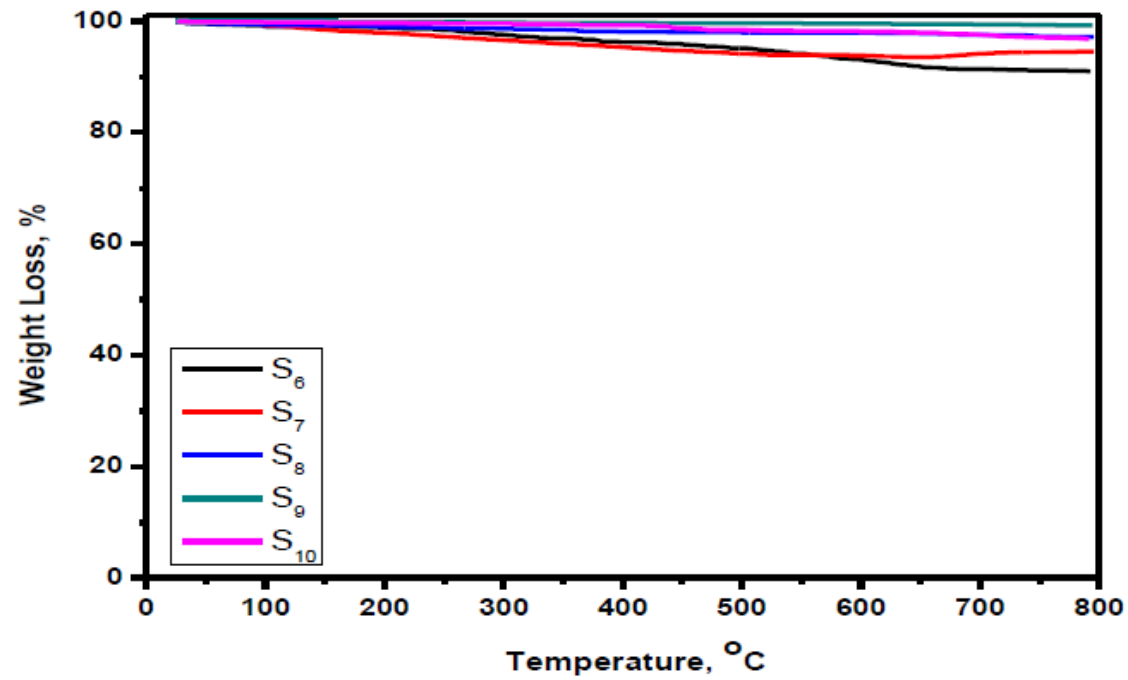

Fig. 9b TG curves of $\mathrm{ZnO}$ nanoparticles synthesized at different temperature 


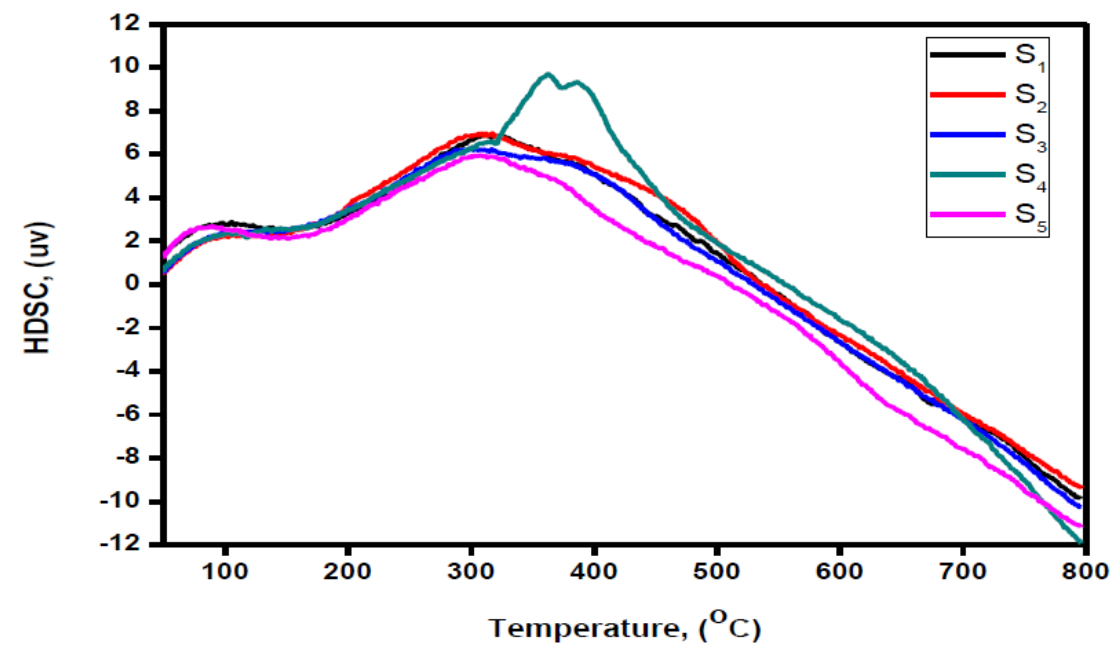

Fig. 10a DSC of ZnO nanoparticles synthesized at different times.

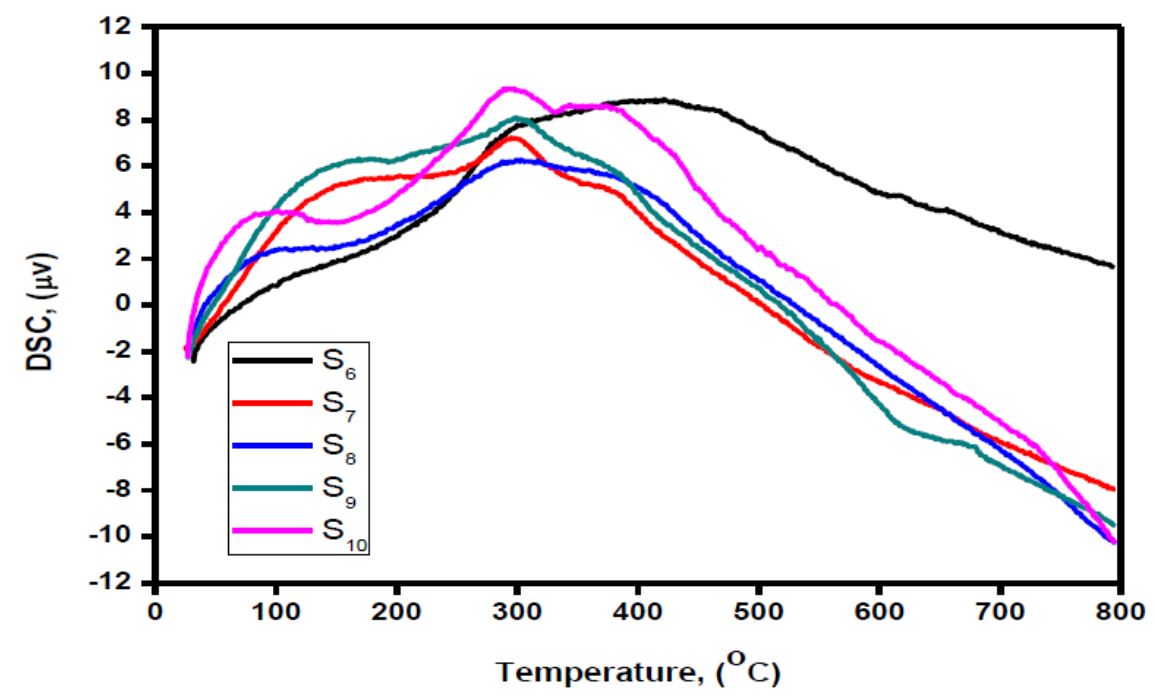

Fig. 10b DSC of ZnO nanoparticles synthesized at different temperature 


\section{$\underline{\text { Tables }}$}

Table 1. The characteristics of the $\mathrm{ZnO}$ nanoparticles synthesized at various time and temperature values.

\begin{tabular}{|c|c|c|c|c|c|c|c|c|c|c|}
\hline \multirow[b]{2}{*}{ NO. } & \multirow[b]{2}{*}{ Factor } & \multirow{2}{*}{$\begin{array}{c}2 \theta(101) \\
\quad\left({ }^{\circ}\right)\end{array}$} & \multirow{2}{*}{$\begin{array}{c}\text { FWHM } \\
\text {, (rad), } \\
\left(\mathbf{1 0}^{-2}\right)\end{array}$} & \multicolumn{2}{|c|}{ D (nm) } & \multirow{2}{*}{$\begin{array}{c}\text { d, } \\
(\mathbf{n m})\end{array}$} & \multirow{2}{*}{$\begin{array}{c}\mathbf{a} \\
(\mathbf{n m})\end{array}$} & \multirow{2}{*}{$\underset{(\mathbf{n m})}{\mathbf{c},}$} & \multirow{2}{*}{$\underset{\left(10^{-3}\right)}{\mathbf{S}}$} & \multirow{2}{*}{$\varepsilon,\left(10^{-3}\right)$} \\
\hline & & & & Scherer & WH & & & & & \\
\hline$S_{1}$ & $8 \mathrm{~h}$ & 36.285 & 0.4662 & 31.30 & 48.14 & 0.2475 & 0.3249 & 0.5205 & 1.02 & 1.1075 \\
\hline $\mathrm{S}_{2}$ & $12 \mathrm{~h}$ & 36.307 & 0.4698 & 31.06 & 61.1 & 0.2475 & 0.3249 & 0.5205 & 1.04 & 1.1161 \\
\hline$S_{3}$ & $16 \mathrm{~h}$ & 36.288 & 0.4388 & 33.25 & 44.7 & 0.2475 & 0.3249 & 0.5205 & 0.90 & 1.0424 \\
\hline $\mathrm{S}_{4}$ & $20 \mathrm{~h}$ & 36.329 & 0.3812 & 38.28 & 48.56 & 0.2475 & 0.3249 & 0.5205 & 0.68 & 0.9055 \\
\hline $\mathrm{S}_{5}$ & $24 \mathrm{~h}$ & 36.282 & 0.4168 & 35.01 & 48.76 & 0.2475 & 0.3249 & 0.5205 & 0.82 & 0.9902 \\
\hline $\mathrm{S}_{6}$ & $100^{\circ} \mathrm{C}$ & 36.264 & 0.5402 & 27.02 & 31.68 & 0.2475 & 0.3249 & 0.5205 & 1.37 & 1.2831 \\
\hline $\mathrm{S}_{7}$ & $125^{\circ} \mathrm{C}$ & 36.256 & 0.5248 & 27.80 & 34.48 & 0.2476 & 0.3250 & 0.5207 & 1.29 & 1.2468 \\
\hline $\mathrm{S}_{8}$ & $150^{\circ} \mathrm{C}$ & 36.264 & 0.4388 & 33.12 & 44.27 & 0.2475 & 0.3249 & 0.5205 & 0.90 & 1.0424 \\
\hline $\mathrm{S}_{9}$ & $175^{\circ} \mathrm{C}$ & 36.256 & 0.4897 & 29.79 & 44.02 & 0.2476 & 0.3250 & 0.5207 & 1.13 & 1.1635 \\
\hline$S_{10}$ & $200^{\circ} \mathrm{C}$ & 36.265 & 0.4157 & 35.10 & 50.99 & 0.2475 & 0.3249 & 0.5205 & 0.81 & 0.9875 \\
\hline
\end{tabular}

Table 2. Band gap values estimated for different reaction times and temperatures.

\begin{tabular}{|c|c|c|c|}
\hline Time, hrs. & $\mathrm{E}_{\mathrm{g}}, \mathrm{eV}$ & Temperature, ${ }^{\circ} \mathrm{C}$ & $E_{g}, e V$ \\
\hline 8 & 3.62 & 100 & 3.60 \\
\hline 12 & 3.40 & 125 & 3.38 \\
\hline 15 & 3.26 & 150 & 3.28 \\
\hline 20 & 3.13 & 175 & 3.18 \\
\hline 24 & 2.90 & 200 & 2.91 \\
\hline
\end{tabular}

